\title{
Dan Edelstein (ed.), The Super-Enlightenment: daring to know too much
}

Jean-Paul De Nola

\section{(2) OpenEdition}

10 Journals

\section{Édition électronique}

URL : http://journals.openedition.org/studifrancesi/5623

DOI : 10.4000/studifrancesi.5623

ISSN : 2421-5856

Éditeur

Rosenberg \& Sellier

\section{Édition imprimée}

Date de publication : 1 septembre 2011

Pagination : 407-408

ISSN : 0039-2944

\section{Référence électronique}

Jean-Paul De Nola, «Dan Edelstein (ed.), The Super-Enlightenment: daring to know too much », Studi

Francesi [En ligne], 164 (LV | II) | 2011, mis en ligne le 30 novembre 2015, consulté le 13 janvier 2021. URL : http://journals.openedition.org/studifrancesi/5623; DOI : https://doi.org/10.4000/studifrancesi. 5623

Ce document a été généré automatiquement le 13 janvier 2021.

\section{(c)}

Studi Francesi è distribuita con Licenza Creative Commons Attribuzione - Non commerciale - Non opere derivate 4.0 Internazionale. 


\title{
Dan Edelstein (ed.), The Super- Enlightenment: daring to know too much
}

\author{
Jean-Paul De Nola
}

\section{RÉFÉRENCE}

DAN EDELSTEIN (ed.), The Super-Enlightenment: daring to know too much, Oxford, Voltaire Foundation, 2010, X + $302 \mathrm{pp}$.

1 Le titre de ce volume collectif pourrait se traduire: Au-delà des Lumières: l'audace d'en savoir trop. Ce titre joue sur les mots dans deux registres: l'érudit (Kant: Sapere aude!) et le «noir» (les gangsters américains: That guy knows too much...). Cela dit, distinguons illuminés (sens surtout péjoratif: visionnaires, fantasques), illuministes ou théosophes (qui s'approchent de Dieu par des moyens surnaturels) et "philosophes» (sens prégnant: partisans des Lumières). Ce qu'on appelle Lumières en France correspond à l'Aufklärung en Allemagne et à l'Enlightenment dans les pays anglo-saxons. Mais en Italie un même drapeau («gli Illuministi») couvre les swedenborghiens et les Encyclopédistes.

D'ailleurs, l'adhésion aux Lumières n'est pas incompatible avec l'appartenance au «dark side» du mouvement, à cet «illuminisme» plutôt mal considéré: «While undoubtedly aberrant, Pernety's example nonetheless raises the interesting question of how Enlightenment principles could coexist, seemingly without difficulty, with those lasting currents of mysticism, magic, mythical speculation and hermeticism that persisted throughout the eighteenth century» (p. 2). Une portion non négligeable de la zone frontalière grise («grey area»), la zone la moins chimérique de l'illuminisme - textes, théories, tendances - pourrait être récupérée, propose Dan Edelstein, en la considérant comme un excès d'Enlightenment, comme un Super-Enlightenment. Cette thèse d'Edelstein est corroborée par Peter REILL (dans le domaine de l'alchimie, de l'hermétique et de l'ésotérisme) et David BATES (qui envisage le Super-Enlightenment comme un excès 
épistémologique). Jessica RUSKIN s'intéresse à l'homme-machine de Julien offray de La Mettrie et Liana VARDIC aux «visions physiocratiques» de François Quesnay. Anthony VIDLER explique l' «illisibilité» du traité sur l'architecture de Claude-Nicolas Ledoux en le mettant en rapport avec l'Hypnerotomachia de Francesco Colonna. Fabienne MOoRE, dans la poésie française du XvIII ${ }^{\mathrm{e}}$ siècle, différencie Enlightenment philosophique (ex. André Chénier), Enlightenment catholique (ex. Jean-Baptiste Rousseau) et SuperEnlightenment: Cazotte, Chassaignon, Mercier, Saint-Martin, Bonneville. Nathalie BAYER parle de la pénétration de la Franc-maçonnerie dans l'Empire russe et de sa difficile conciliation avec l'Église orthodoxe, tandis que Kris PANGBURN présente la théorie de Charles Bonnet sur la palingénésie. Dan EDELSTEIN, l' «editor» lui-même de ce riche volume, explique l'intérêt de la France révolutionnaire pour l'Égypte des pharaons, patrie présumée de l' «âge d'or». Et Tili Boon cuillé examine les reflets en France du succès d'Ossian dans les domaines de la littérature (Mme de Staël), de la peinture (Girodet) et de l'opéra (Le Sueur). 